\title{
28 Research Square \\ Results of a novel surgical technique for iridodialysis repair using segments
}

\section{Ugur Unsal}

Batigoz Hospital

Huri Sabur ( $\nabla$ dr_hurisabur@hotmail.com )

Bergama Necla-Mithat Ozture State Hospital https://orcid.org/0000-0002-3071-6240

\section{Mehmet Soyler}

Batigoz Hospital

\section{Research Article}

Keywords: iridodialysis repair, trauma, surgical technique, segment

Posted Date: April 28th, 2021

DOI: https://doi.org/10.21203/rs.3.rs-339853/v1

License: (c) (i) This work is licensed under a Creative Commons Attribution 4.0 International License. Read Full License

Version of Record: A version of this preprint was published at International Ophthalmology on August 22nd, 2021. See the published version at https://doi.org/10.1007/s10792-021-02016-4. 


\section{Abstract}

Purpose: To describe a novel surgical technique for iridodialysis repair using iris retractor segments and report its clinical results.

Methods: 53 eyes of 53 patients who underwent surgery for iridodialysis repair were enrolled in this retrospective study. Data recorded from patient files consisted of age, sex, history of trauma, surgical indications and type of surgery, preoperative and postoperative corrected distance visual acuity (CDVA), intraocular pressure (IOP), complications, and follow-up time. The novel, minimally invasive surgical technique was explicitly described in detail.

Results: Mean follow-up time was 34.4 (range 12-84) months. The subjects were 29 (54.7\%) men and 26 $(45.3 \%)$ women, and the mean age was $56.6 \pm 14.0$ years. Iridodialysis repair performed using one segment in $37(69.8 \%)$ eyes, two segments in 15 (28.3\%) eyes, and three segments in $1(1.9 \%)$ eye. Pupilloplasty was performed in 17 eyes due to wide pupil diameter. The iridodialysis repair was combined with lens removal in 48 eyes, and anterior vitrectomy was performed in 10 eyes. CDVA significantly improved after surgery $(\mathrm{p}<0.001)$. Post-traumatic IOP rise was the most common complication, and six patients needed medical therapy for glaucoma control.

Conclusion: Iridodialysis repair using iris retractor segment is a minimally invasive technique and found to be safe and effective, providing less surgical manipulation and surgical time than other techniques.

\section{Introduction}

Iridodialysis can be encountered as a complication of blunt trauma and anterior segment surgery. As the iris root is weaker and thinner than the other parts of the iris, this area is vulnerable to post-traumatic injury [1]. Although surgical treatment is not required in small iridodialysis, larger iridodialysis causing polychoria, diplopia, and photophobia should be repaired.

There are various methods described for iridodialysis repair [2-12]. Iris suturation is the most preferred method, but complications like lens capsule tear, hyphema, anterior chamber reaction, intraocular pressure rise, and corectopia can be seen [2-5].

Herein, we describe a novel, minimally invasive technique for managing different degrees of iridodialysis using an iris retractor segment. This technique promises pleasing anatomical and cosmetic results avoiding excessive surgical manipulations and long surgical time. Our aim in this study is to show the technique and report the surgical outcomes of this new surgical procedure.

\section{Methods}


The data of 75 patients who underwent iridodialysis repair between March 2008 to April 2019 were revised retrospectively, and patients with incomplete data and those with a follow-up period of fewer than 12 months were excluded. Fifty-three patients met the inclusion criteria and enrolled in the study. Ethical approval was waived by the Local Ethics Committee of Izmir Bakircay University, and the study was performed according to the principles of the Declaration of Helsinki. Written informed consent was provided from each patient.

The patients were operated under the sub-tenon anesthesia using a mixture of $2 \mathrm{ml}$ lidocaine (2\%) and 2 $\mathrm{ml}$ bupivacaine $(0.75 \%)$. All the surgeries performed by the same surgeons (UU and MS) with the following surgical steps. A conjunctival limbal peritomy was made at the side of the iridodialysis. Corneal side ports were made by a $20 \mathrm{G}$ MVR blade, and a cohesive ophthalmic viscosurgical device (OVD, Healon, $1.0 \%$ ) was injected into the anterior chamber. A spatula was used to check and break the adhesions between the iris and anterior lens capsule. According to the degree of iridodialysis, a segment was cut from the flat part of a disposable iris retractor (Biotech) (Figure 1, a). A clear corneal incision of $2.2 \mathrm{~mm}$ (1.8 mm for iridodialysis repair only, $2.2 \mathrm{~mm}$ for combined cases) in size was made from the opposite side of iridodialysis. A PC-9 suture (Alcon Surgical) needle was inserted into the incision, moved under the iris, passed through the iridodialysis edge, and exited from $1.5 \mathrm{~mm}$ away from the limbus (Figure 1, b). The segment was then tied from the middle by a PC-9 prolene suture (Figure 1, c). While the sutured segment was pulled slowly, care was taken to keep the segment under the iris. With the help of the segment, the iridodialysis area was fixed to the iris root (Figure 1, d). The suture's free end was then buried using the suture burial technique of Baykara [13]. (Figure 1, e). The OVD was aspirated with a bimanual irrigation-aspiration system, and corneal incisions were hydrated. The conjunctiva was closed with an 8-0 vicryl suture (Figure 1, f). Finally, $1.0 \mathrm{mg} / 0.1 \mathrm{ml}$ cefuroxime (Aprokam) was injected into the anterior chamber for endophthalmitis prophylaxis. According to the degree of iridodialysis, one or more segments can be used to close the defect. The surgical technique for wide defects was shown in Figure 2 in detail. A demonstrative video showing the surgical steps is available as an online resource (Online Resource 1).

Phacoemulsification was performed using the phaco chop technique with Infiniti ${ }^{\circledR}$ Ozil Intelligent Phaco system (Alcon Surgical) in combined cases. A capsular tension ring was used in zonular dialysis cases. If necessary, anterior vitrectomy and pupilloplasty using Siepser's sliding knot technique [14] were performed in complicated cases. Topical antibiotics and corticosteroids were administered to all patients five times a day for one month.

\section{Statistical methods}

Frequency and percentage values were used for categorical variables. Mean \pm standard deviation or median (minimum-maximum) values were used for continuous variables. The distribution of continuous variables was tested by Kolmogorov-Smirnov test. For dependent variables that did not show a normal distribution, the comparison of the two groups was made by the Wilcoxon Signed-Rank test. $P<0.05$ was 
considered statistically significant. Analyzes were carried out using the SPSS 23.0 (Statistical Package for the Social Sciences) package program.

\section{Results}

A total of 53 eyes of 53 patients who had iridodialysis repair using iris retractor segment and met the inclusion criteria were enrolled in this study. The subjects were 29 (54.7\%) men and 26 (45.3\%) women, and the mean age was $56.6 \pm 14.0$ years. Mean follow-up time was 34.4 (range 12-84) months. All the patients had a history of blunt trauma, and 28 (52.8\%) eyes had 60 to 90 degrees, 20 (37.7\%) eyes had 91 to 180 degrees, and the remaining $5(9.5 \%)$ eyes had 181 to 270 degree of iridodialysis. The clinical data of patients were shown in Table 1.

Forty-eight eyes had complicated cataract and lens subluxation with iridodialysis, and these eyes underwent cataract surgery with iridodialysis repair. A capsular tension ring was inserted in 46 eyes during cataract surgery due to zonular dialysis. Anterior vitrectomy was performed in 10 eyes with vitreous prolapsus into the anterior chamber due to lens subluxation. While a single segment was adequate for iridodialysis repair in 37 (69.8\%) eyes, two segments were used in $15(28.3 \%)$ eyes, and three segments were used in $1(1.9 \%)$ eye with a 260 degree of iridodialysis. Due to wide pupil, 17 eyes underwent pupilloplasty using Siepser's sliding knot technique, and pupil shape restored to round in all eyes.

Compared to preoperative values, corrected distance visual acuity (CDVA) significantly increased $(p<0.001)$, and intraocular pressure $($ IOP) values significantly decreased $(p<0.001)$. Pleasing anatomical and cosmetic results were achieved in all patients.

The most common complication was post-traumatic IOP rise, and six patients needed medical therapy to be controlled, and this condition is defined as post-traumatic glaucoma. Glaucoma surgery was not required in any patient. Gonioscopy examination was performed at 6 and 12 months after the surgery, and no peripheral anterior synechia or angle-closure was obtained in any of the patients. Preoperative and postoperative complications were shown in Table 2.

\section{Discussion}

All eye structures, especially iris root, can be affected by blunt trauma and may result in iridodialysis. Suturing the iris is the most preferred method for iridodialysis repair. However, sutureless techniques such as iatrogenic incarceration of the iris from the iridodialysis area and isoexpansile sulfur hexafluoride gas usage have also been tried [8,9]. Many different sutural techniques have been mentioned in the literature regarding the management of iridodialysis [2-7,10-12]. These techniques can be divided into two groups, depending on whether they are performed with open or closed chamber techniques or appositional or non-appositional. 
Since minimally invasive methods are preferred, open chamber methods have been replaced by closed chamber techniques. In a closed chamber appositional repair, the iridodialysis area is tightly sutured to the sclera. Several methods has been described in the literature. While Nunziata et al. [2] used a $17.0 \mathrm{~mm}$ straight needle and 10-0 prolene suture, Wachler et al. [3] performed surgeries with a $17.0 \mathrm{~mm}$ doublearmed McCannel suture. Bardak et al. [4] described a method in which a 10-0 prolene suture was passed through a $27 \mathrm{G}$ needle.

The Non-appositional method was first defined by Synder et al. [5], and it was possible to titrate the suture's tightness. Compared to appositional methods, because of the advantages of preventing peripheral anterior synechia and occlusion of the trabecular meshwork, non-appositional methods have become more popular. This technique was improved by Narang et al. [6] by using a trocar system to avoid corneal fiber stuck into the needle and Agarwal et al. [7] by using a 26-gauge needle to guide the suture. Also, knotless technique [10], single-knot sewing machine suture [11], and double-flanged polypropylene suture [12] are other minimally invasive approaches for iridodialysis repair.

An iris retractor stretches and stabilizes the iris during cataract surgery and helps to maintain a safe pupillary diameter. In addition, it can also be used to support capsules in zonular dialysis cases [15-17]. Herein, we used disposable iris retractors made from modified suture material (blue polypropylene monofilament) to support the iridodialysis area. It is not easy to control the needle in the anterior chamber in previous techniques, and several surgical manipulations are needed to close the wider iridodialysis areas. Our technique is so simple that with the help of the iris retractor segment, more iridodialysis areas can be closed at once. It is possible to close up to 90 degrees of iridodialysis with only one segment, and with the help of two segments, nearly 180 degrees of iridodialysis can be closed. Also, the tightness of the suture can be adjusted like non-appositional methods.

To the best of our knowledge, there is no published surgical technique using segments for iridodialysis repair. The main advantage of this technique is that the needle is used in only one direction, and a single suture can be used for several knots, unlike the techniques using double-armed suture. Also, fewer surgical manipulations are required to close wider defects than other techniques, and the surgical time is relatively short for an iridodialysis repair. Thus, possible complications such as lens injury, endothelial damage due to surgical trauma can be prevented. In addition, the learning curve of the surgery is so short and can be performed by any cataract surgeon.

The only limitation of our technique may be the segment cost. However, iridodialysis is often seen in traumatic patients with cataracts, zonular dialysis, and vitreous prolapse, as in our study. In such cases, an iris retractor is used to stabilize the dialysis area during cataract surgery or to provide capsular support in the presence of zonular dialysis. Thus, using the iris retractor segment for iridodialysis repair does not create an extra cost.

\section{Conclusion}


In conclusion, This technique promises a pleasing anatomical and cosmetic result avoiding excessive surgical manipulations and long surgical time. Iris retractor segment acts like a pillow and helps to close more dialysis area at once. Thus, it will be the right choice, especially for patients with wider iridodialysis. The needle is used in only one direction, and a single suture can be used for several knots, unlike the techniques using double-armed suture. Studies comparing with other techniques and involving more patients are needed.

\section{Declarations}

Funding: The authors obtained no commercial provider for the investigation, authorship, and broadcasting of the study.

Conflict of Interest: The authors declare they have no financial conflict of interest related to this article.

Consent for participate and publication: The authors declare they have participated in this work, and they have reviewed the final version of the work, believe it represents valid work, and approve it for publication.

Availability of data and material: The datasets used and analyzed during the current study are available from the corresponding author on reasonable request.

Authors' contributions: U.U conceived the idea. U.U and M.S performed surgeries and U.U collected the data. H.S analyzed the data and H.S wrote the manuscript. U.U, M.S and H.S revised the manuscript. All authors approved the final version.

\section{Acknowledgments}

Muhammed llyas, Ph.D., provided assistance with statistics and English-language editing.

\section{Compliance with ethical standards}

Conflict of Interest: The authors declare they have no financial conflict of interest related to this article.

Ethics approval and consent to participate: All procedures performed in studies involving human participants were in accordance with the ethical standards of Faculty of Medicine, Bakırcay University/Izmir. All procedures conformed to the tenets of the Declaration of Helsinki. Written informed consent was obtained from all individual participants included in the study.

\section{References}

1. Kumar S, Miller D, Atebara N, Blance E (1990) A quantitative animal model of traumatic iridodialysis. Acta Ophthalmol (Copenh) 68(5):591-596. https://doi.org/10.1111/j.1755-3768.1990.tb04794.x

2. Nunziata BR (1993) Repair of iridodialysis using a 17-millimeter straight needle. Ophthalmic Surg 24(9):627-629. PMID: 8233338. 
3. Wachler BB, Krueger RR (1996) Double-armed McCannell suture repair for repair of traumatic iridodialysis. Am J Ophthalmol 122(1):109-110. https://doi.org/10.1016/s0002-9394(14)71971-3

4. Bardak Y, Ozerturk Y, Durmus M, Mensiz E, Aytuluner E (2000) Closed chamber iridodialysis repair using a needle with a distal hole. J Cataract Refract Surg 26(2):173-176. https://doi.org/10.1016/s0886-3350(99)00365-x

5. Snyder ME, Lindsell LB (2011) Nonappositional repair of iridodialysis. J Cataract Refract Surg 37(4):625-628. https://doi.org/10.1016/j.jcrs.2011.02.001

6. Narang P, Agarwal A (2020) Trocar assisted non-appositional repair of iridodialysis. Eur J Ophthalmol:1120672120948747. https://doi.org/10.1177/1120672120948747 Epub ahead of print.

7. Agarwal T, Singh D, Panda A (2011) Guide needle-assisted iridodialysis repair. J Cataract Refract Surg 37(10):1918; author reply 1918-1919. https://doi.org/10.1016/j.jcrs.2011.08.009

8. Aron N, Sinha R, Sharma N, Agarwal T (2018) Isoexpansile sulfur hexafluoride gas to repair near-total iris disinsertion. J Cataract Refract Surg 44(10):1175-1178. https://doi.org/10.1016/j.jcrs.2018.06.024

9. Richard JC, Kennedy CJ (2006) Sutureless technique for repair of traumatic iridodialysis. Ophthalmic Surg Lasers Imaging 37(6):508-510. https://doi.org/10.3928/15428877-20061101-14

10. Voykov B (2016) Knotless technique for iridodialysis repair. Clin Exp Ophthalmol 44(2):135-136. https://doi.org/10.1111/ceo.12586

11. Silva JL, Póvoa J, Lobo C, Murta J (2016) New technique for iridodialysis correction: Single-knot sewing-machine suture. J Cataract Refract Surg 42(4):520-523.

https://doi.org/10.1016/j.jcrs.2016.03.021

12. Kusaka M, Miyamoto N, Akimoto M (2019) Repairing iridodialysis by riveting with double-flanged polypropylene suture. J Cataract Refract Surg 45(11):1531-1534. https://doi.org/10.1016/j.jcrs.2019.08.001

13. Baykara M (2004) Suture burial technique in scleral fixation. J Cataract Refract Surg 30 (5):957-959. https://doi.org/10.1016/j.jcrs.2003.09.048

14. Siepser SB (1994) The closed-chamber slipping suture technique for iris repair. Ann Ophthalmol 26(3):71-72. PMID: 7944159

15. Nova'k J (1997) Flexible iris hooks for phacoemulsification. J Cataract Refract Surg 23(6):828-831. https://doi.org/10.1016/s0886-3350(97)80238-6

16. Lee V, Bloom P (1999) Microhook capsule stabilization for phacoemulsification in eyes with pseudoexfoliation-syndrome-induced lens instability. J Cataract Refract Surg 25(12):1567-1570. https://doi.org/10.1016/s0886-3350(99)00264-3

17. Tsai $\mathrm{CH}$, Hsiao $\mathrm{CH}, \mathrm{Ku}$ WC (2006) Flexible iris retractors for management of zonular dialysis during planned phacoemulsification. Chang Gung Med J 29(5):499-504.PMID: 17214395

\section{Tables}


Table 1. Clinical data of the patients

\begin{tabular}{|c|c|c|}
\hline Age $(y)$, mean $\pm S D$ & $56.60 \pm 14.03$ & \\
\hline Sex (men/women) & $29 / 24$ & \\
\hline \multicolumn{3}{|c|}{ Degree of iridodialysis, n (\%) } \\
\hline$<90$ degree & $20(37.7)$ & \\
\hline 90-180 degree & $28(52.8)$ & \\
\hline$>180$ degree & $5(9.5)$ & \\
\hline $\begin{array}{l}\text { Preop CDVA (logMAR) } \\
\text { median (min-max) }\end{array}$ & $0.7(1.8-0.0)$ & $p<0.001^{*}$ \\
\hline $\begin{array}{c}\text { Postop CDVA (logMAR) } \\
\text { median (min-max) }\end{array}$ & $0.1(0.4-0.0)$ & \\
\hline $\begin{array}{l}\text { Preop IOP (mm Hg) } \\
\text { median (min-max) }\end{array}$ & $20(12-32)$ & $p<0.001 *$ \\
\hline $\begin{array}{l}\text { Postop IOP (mm Hg) } \\
\text { median (min-max) }\end{array}$ & $18(12-24)$ & \\
\hline
\end{tabular}

*Wilcox Signed-Rank test, SD: standard deviation, CDVA: corrected distance visual acuity, LogMAR: logarithm of minimal angle of deviation, IOP: intraocular pressure

Table 2. Preoperative and postoperative complications

\begin{tabular}{|lcl|}
\hline Post-traumatic IOP elevation, $\mathrm{n}(\%)$ & $13(24.5)$ \\
\hline Post-traumatic glaucoma, $\mathrm{n}(\%)$ & 6 & $(11.3)$ \\
\hline Corneal edema, $\mathrm{n}(\%)$ & 2 & $(3.8)$ \\
\hline Mild hyphema, $\mathrm{n}(\%)$ & 1 & $(1.9)$ \\
\hline Cataract, $\mathrm{n}(\%)$ & $1(1.9)$ \\
\hline
\end{tabular}

IOP: intraocular pressure

\section{Figures}




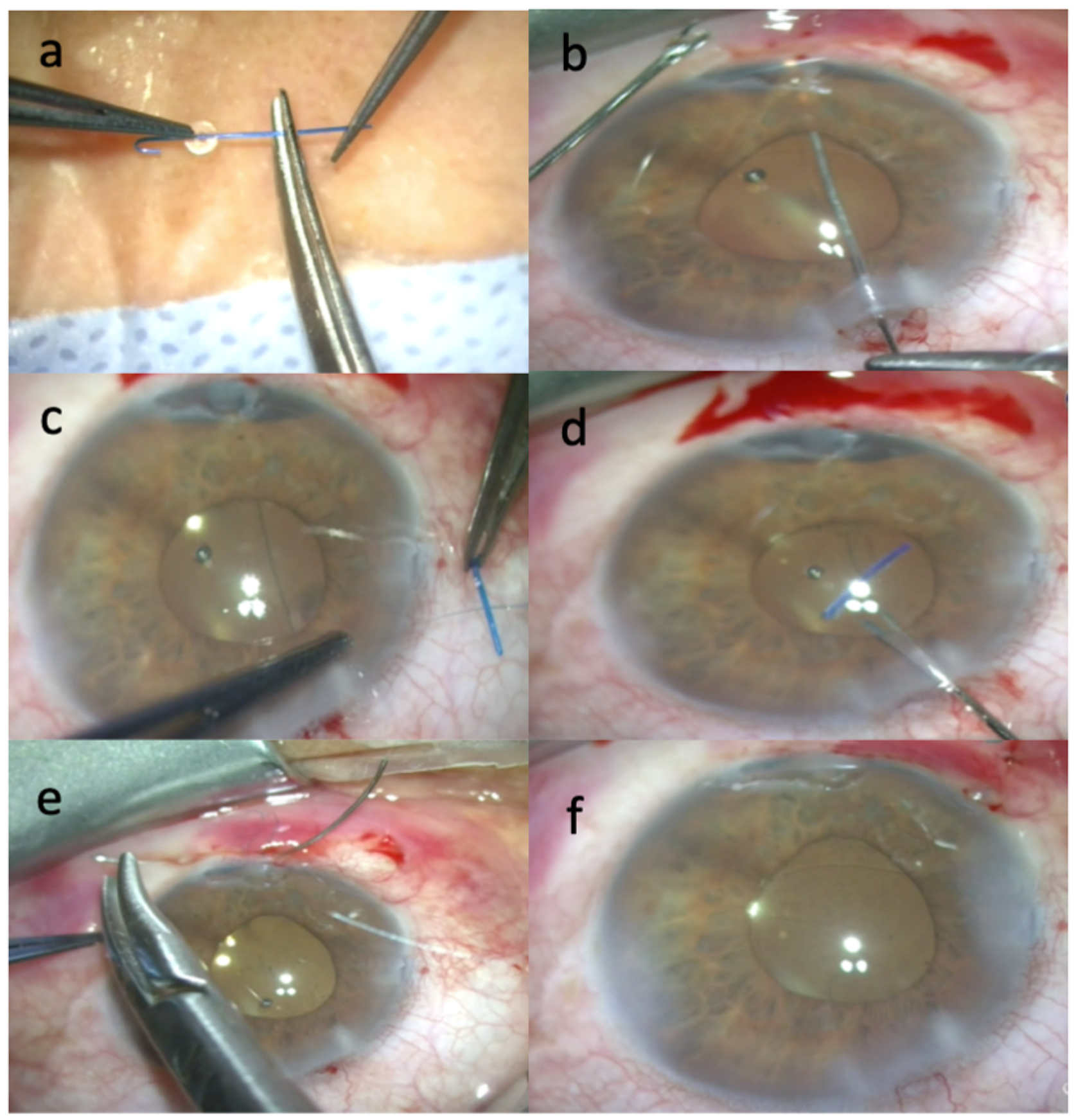

\section{Figure 1}

The surgical steps of the iridodialysis repair up to 90 degrees with one iris retractor segment. 1a: A segment was cut from the flat part of a disposable iris retractor. $1 \mathrm{~b}$ : A clear corneal incision of $2.2 \mathrm{~mm}$ in size was made from the opposite side of iridodialysis, and a PC-9 suture needle was inserted into the incision, moved under the iris, passed through the center of the iridodialysis edge, and exited from the sclera. 1c: The segment was tied from the middle by PC-9 prolene suture 1d: The sutured segment was 
pulled slowly, moved under the iris, and the iridodialysis area was fixed to the iris root with the help of the segment.1e: The free end of the suture was buried to the sclera. 1f: Corneal side ports were hydrated, and conjunctiva was closed.

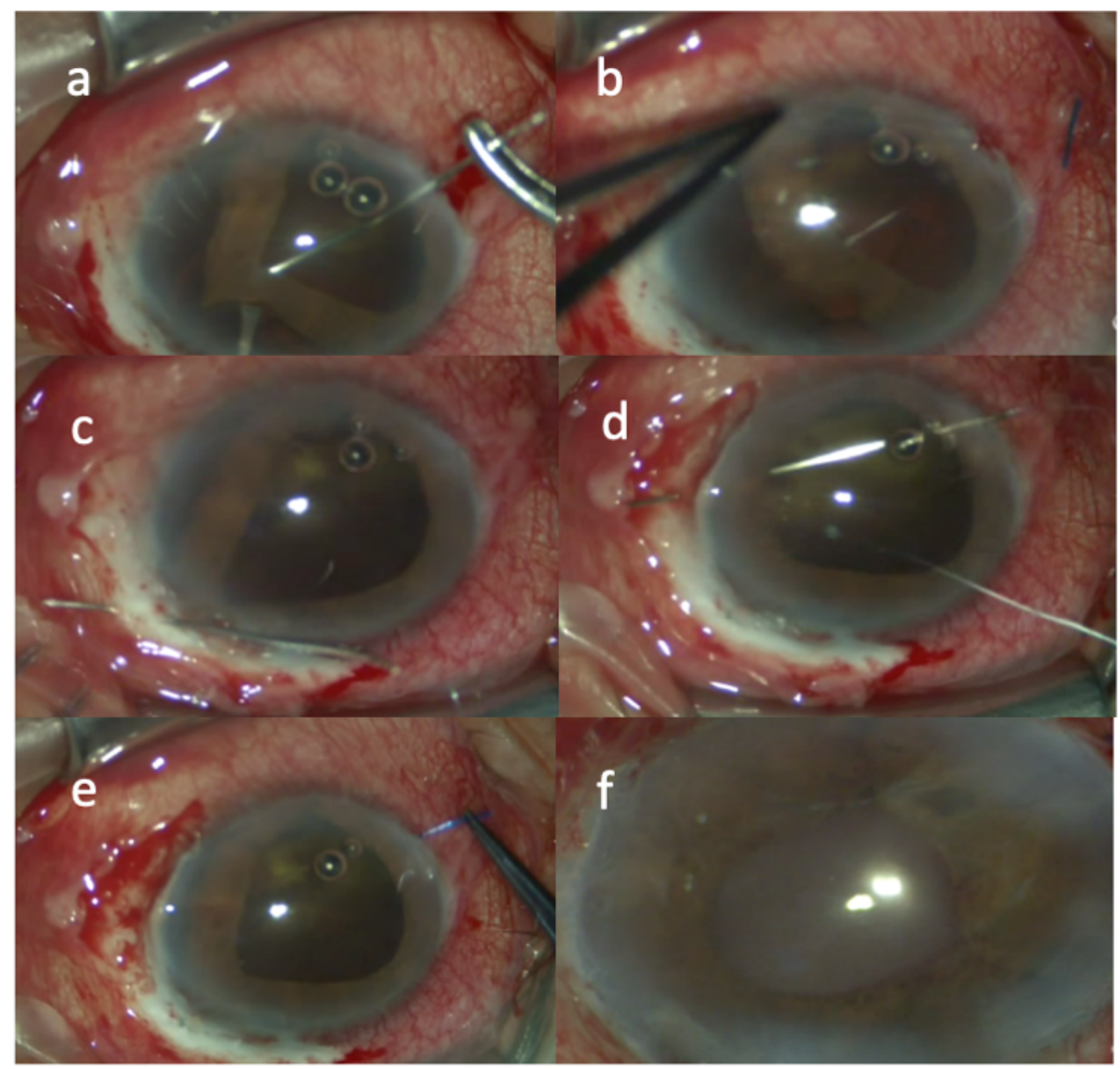

Figure 2

The surgical steps of the iridodialysis repair more than 90 degrees with multiple iris retractor segments. 2a: After performing a conjunctival limbal peritomy at the side of the iridodialysis area and a clear corneal incision at the opposite side, a PC-9 suture needle was inserted into the incision, moved under the 
iris, passed from the middle of the iridodialysis area. $2 \mathrm{~b}$ : The PC-9 suture was inserted into the middle of the segment, cut from the iris retractor before. 2c: The sutured segment was pulled slowly, the iridodialysis area was fixed to the iris root with the help of the segment, and the suture is buried into the sclera. 2d,e: The remaining iridodialysis defect was closed with another segment using the following steps described above. 2f: A pupilloplasty was done using Siepser's sliding knot technique.

\section{Supplementary Files}

This is a list of supplementary files associated with this preprint. Click to download.

- OnlineResource1.mp4 